Part of Journal of Research of the National Bureau of Standards, Volume 28, April 1942

\title{
STRUCTURAL CHANGES IN THE BONDING LAYER OF SOFT-SOLDERED JOINTS IN COPPER PIPE LINES ON LONG-CONTINUED HEATING
}

\author{
By William H. Swanger and Arthur R. Maupin ${ }^{1}$
}

\section{ABSTRACT}

In the course of previous investigations $[1,2]^{2}$ to establish the merits of soldered joints in copper-tube lines for domestic plumbing and other purposes, it became evident that in the evaluation of such joints consideration must be given to possible deterioration with time of the bond of the soldered joint if the service involves use at elevated temperatures. Joints made with solder containing tin were found to be susceptible to such a change, under favorable circumstances, whereas many lead-base solders were not. By means of metallographic studies of specimens cut from soldered joints held at elevated temperature for long periods, the nature of the microstructural change was established and correlated with the lowering of the bonding properties of the soldered joint. Essentially, this consists in the formation of a bonding layer adjacent to the copper base by alloying, by diffusion, of the tin of the solder and the adjacent copper. Microhardness determinations showed this constituent to be much harder than the initial solder and also harder than the copper base. Evidence of brittleness was also found. Most tin-free lead-base solders, including lead-silver solder, were found not to be susceptible of this change. Lead-cadmium solder was an exception.

\section{CONTENTS}

I. Introduction _._.

II. The soldered joint-construction and use

III. Metallographic study of soldered joints - results and discussion_..... 481

1. General discussion $\ldots \ldots \ldots 1$

2. Solders containing tin

(a) $(50-50)$ tin-lead

(b) (60-39-1) lead-tin-antimony and (95-5) lead-tin ..... 484

(c) (95-5) tin-antimony solder $\ldots$

3. Lead-base tin-free solders . . . . . . .

(a) Lead-silver

(b) Lead-cadmium-zinc $\ldots \ldots \ldots$ _ 485

(c) High-purity lead. . . . .

IV. Conclusions _...

V. References_...

\section{INTRODUCTION}

Previous investigations $[1,2]$ on the use of soft-soldered joints in copper-pipe lines for domestic plumbing and for other purposes have shown that strength measurements at room and at elevated tempera-

\footnotetext{
${ }_{1}$ Research Associate at the National Bureau of Standards, representing the Copper \& Brass Research Association.

${ }_{2}^{2}$ Figures in brackets indicate the literature references at the end of this paper.
} 
tures do not yield sufficient information on which complete evaluation of the permanence of such joints in service can be based. In addition to the information obtained by long-time loading tests carried out at the temperatures expected in service, consideration must be given to the possible deterioration with time of the "bond" between the solder film and the copper in the joints. This is especially necessary if the service conditions involve long periods at temperatures considerably above normal atmospheric temperature, though below the lower limit of the melting range of the solder.

The previous study has shown that when used on copper and copperbase alloys, soft solders containing tin as an essential constituent are susceptible of deterioration of the "bond", at temperatures approaching $250^{\circ} \mathrm{F}$, involving loss of strength and other undesirable changes [1]. Tin-alloy solders, therefore, should not be recommended for joining copper that is to be used for extended periods at temperatures above $250^{\circ} \mathrm{F}$. Lead-base solders, free from tin, were found not to be susceptible of such deteriorations of the bond on copper. Within the necessary strength limitations [2], joints made with the lead-base solders investigated can be used with safety at temperatures up to $325^{\circ} \mathrm{F}$.

In order to determine the nature of the changes which occur in the solder films, a metallographic study was made of these joints after exposing them to the appropriate temperatures for various periods of relatively long duration.

\section{THE SOLDERED JOINT-CONSTRUCTION AND USE}

Although the work described in this report was restricted to soldered sleeve joints of the type used in copper-tube plumbing lines, it is obvious that the results are representative of all joints made with the same solders on copper as the base material. Presumably also the results are typical of similar soldered joints on various alloys of which copper is the predominating component. The results of some tests on soldered joints in brass are confirmatory of this.

Figure 1 shows the outward appearance of a soldered sleeve joint in copper tubing, together with a longitudinal section to show the location of the solder film.

In making any kind of soldered joint, an initially clean surface is necessary. Removal of the surface tarnish film, grease, or other contamination by abrasion or scraping, so as to expose bright metal, is common practice. Use of a flux at the soldering temperature is necessary. In the present work zinc chloride or a mixture of zinc and ammonium chlorides was used. These fluxes are molten at the soldering temperature and exert a further cleansing action on the base metal and also prevent oxidation of base metal surface and solder by blanketing them from the air. The "wetting" or spread of the solder on"the surface and the ability of the molten solder to fill by capillary action the crevice between the surfaces to be joined is also promoted by the flux. In fact, if the fluxing action is not obtained, the solder will not spread out in a thin film but will tend to coalesce on the surface or fail to penetrate a crevice by capillary action.

Wetting of the surface occurs most readily when there is some alloying between a component of the solder and the metal with which it is in contact. Alloying between copper and the tin constituent of 


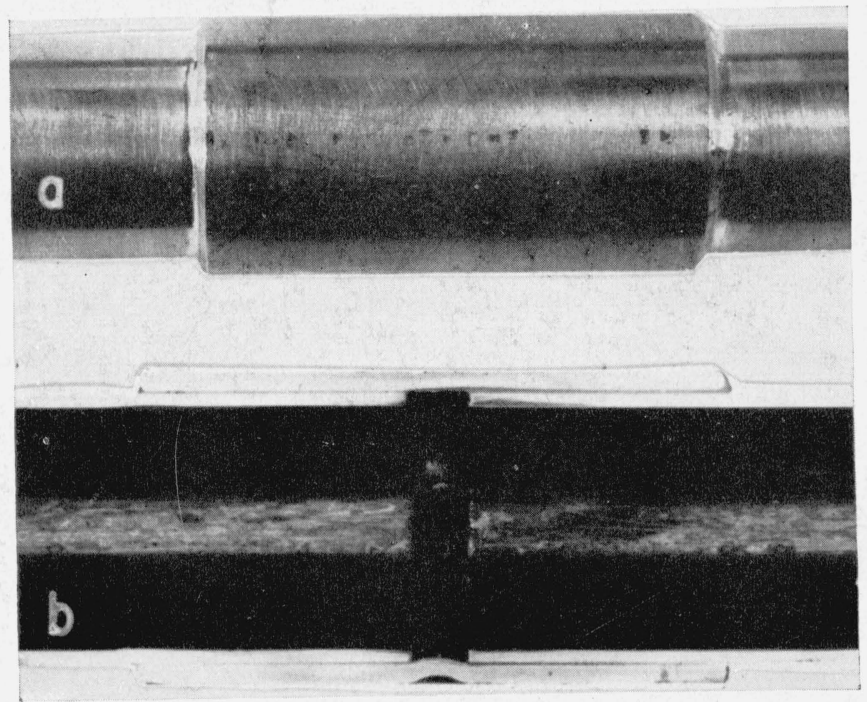

Figure 1.-Soldered sleeve joint in copper-tube plumbing line, $\times 1$.

(a) External appearance; (b) longitudinal section showing the solder film. 

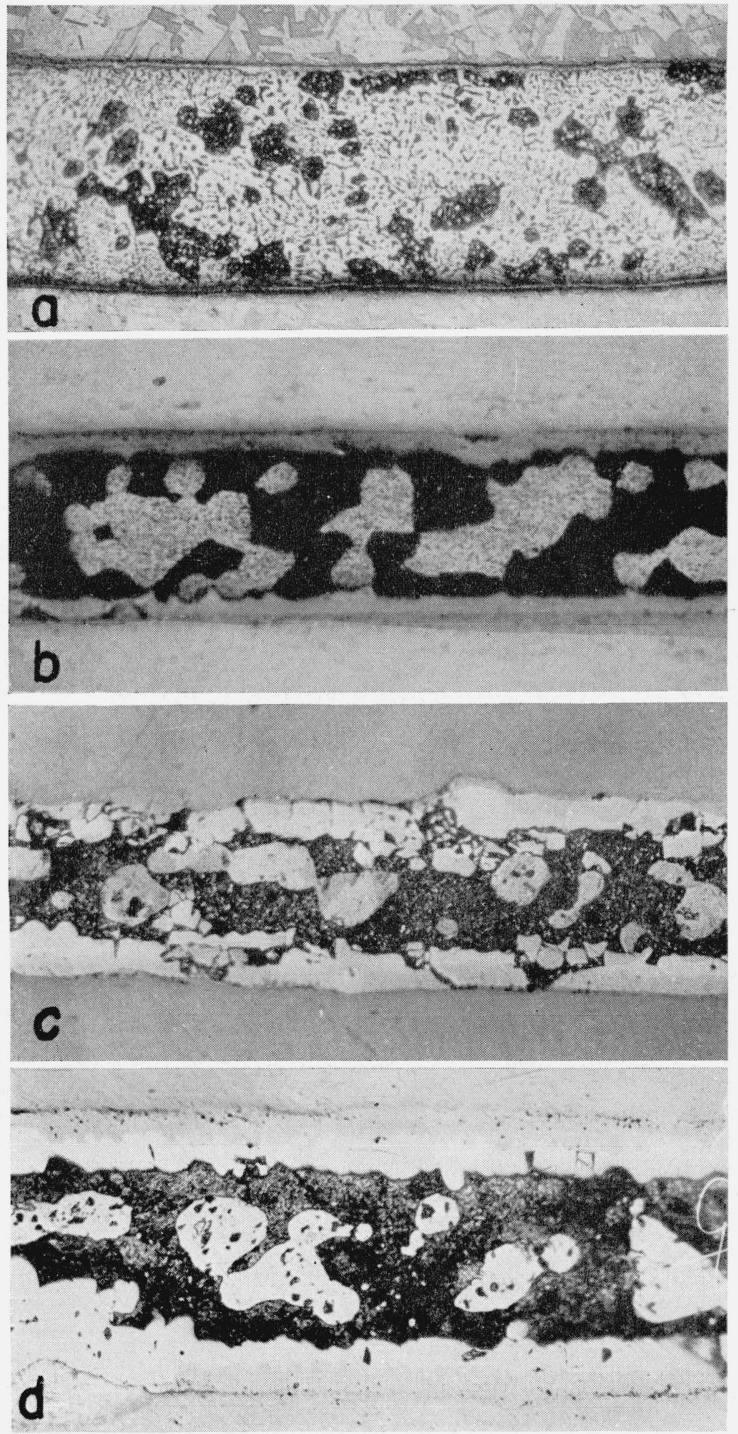

FIGURE 3.-Structural changes in the solder film in a copper-tube joint, (50-50) tinlead solder, $\times 250$.

(a) Initial structure of the solder film, consisting of the tin-lead eutectic embedded in which are dendrites of the excess lead, etched. A thin bonding laver was formed by alloying of tin from the solder with the copper base; (b) solder film in a joint maintained at $250^{\circ} \mathrm{F}$ for 7,500 hours under a tensile shear stress of $70 \mathrm{lb} /$ in. $^{2}$, unetched. Note the increased thickness of the bonding-alloy layer $\left(\mathrm{Cu}_{3} \mathrm{Sn}\right)$ and the pronounced coalescence of the structural constituents within the solder film; (c) solder film in a joint maintained for 12,000 hours at $250^{\circ} \mathrm{F}$ under a tensile shear stress of $70 \mathrm{lb} / \mathrm{in}^{2} .^{2}$ for first 5,000 hours, and $90 \mathrm{lb} / \mathrm{in} .{ }^{2}$ for 7,000 hours, unetched. Note marked increase in the alloy $\left(\mathrm{Cu}_{3} \mathrm{Sn}\right)$ layer and its cracked condition; (d) solder film in a joint maintained for 28,000 hours at $250^{\circ} \mathrm{F}$ under a tensile shear stress of $70 \mathrm{lb} / \mathrm{in} .2$ for 5,000 hours; $90 \mathrm{lb} /$ in $^{2}$ for 7,000 hours; and zero stress, 16,000 hours; unetched. Note the duplex structure of the alloy layer; the white constituent is $\mathrm{Cu}_{3} \mathrm{Sn}$. 

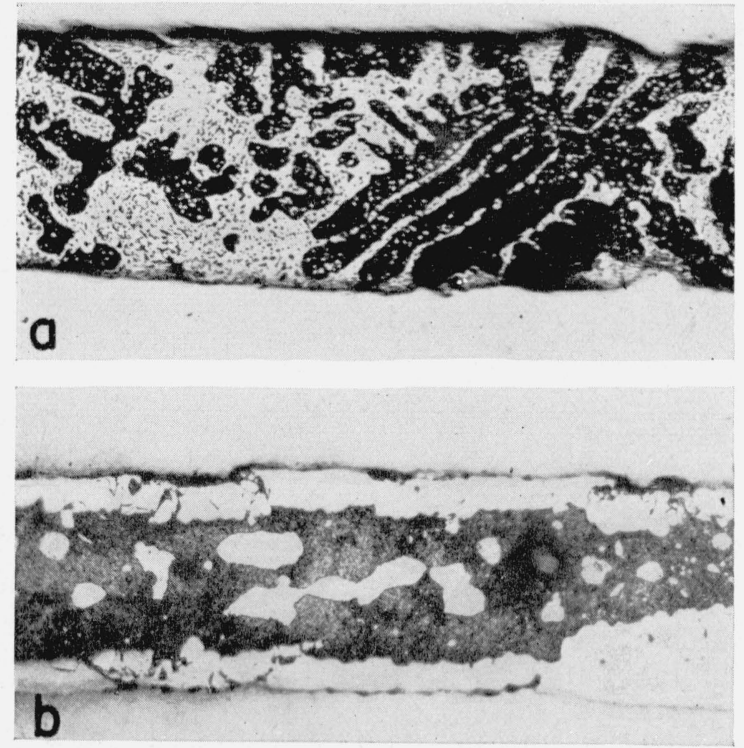

FIGURE 4.- Structural changes in the solder film in a copper-tube joint, (60-39-1) lead-tin-antimony solder, $\times 250$.

(a) Initial structure of solder film, unetched; this is comparable with the structure shown in figure 3 (a) (b) solder film in a joint maintained at $250^{\circ} \mathrm{F}$ for 12,500 hours under a tensile shear stress of $90 \mathrm{lb} / \mathrm{in} .^{2}$, unetched. Compare with figure 3 (c). 

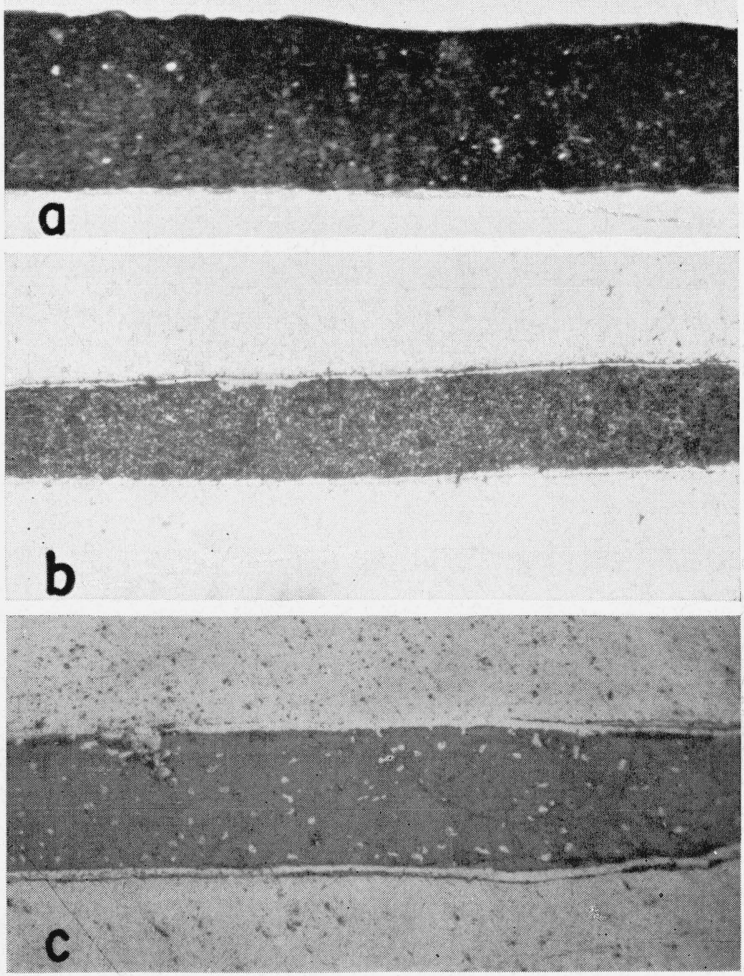

FigURE 5.- Structural changes in the solder film in copper-tube joint, (95-5) lead-tin solder, unetched, $\times 250$.

(a) Initial structure of solder film; (b) solder film in a joint maintained at $250^{\circ} \mathrm{F}$ for 7,200 hours under a tensile shear stress of $180 \mathrm{lb} / \mathrm{in}^{2}$. Some trace of a bonding-alloy layer can be seen; (c) solder film in a joint maintained at $325^{\circ} \mathrm{F}$ for 6,800 hours under a tensile shear stress of $160 \mathrm{lb} / \mathrm{in}^{2}$. Note the bonding-alloy layer and the coalescence within the solder film. 


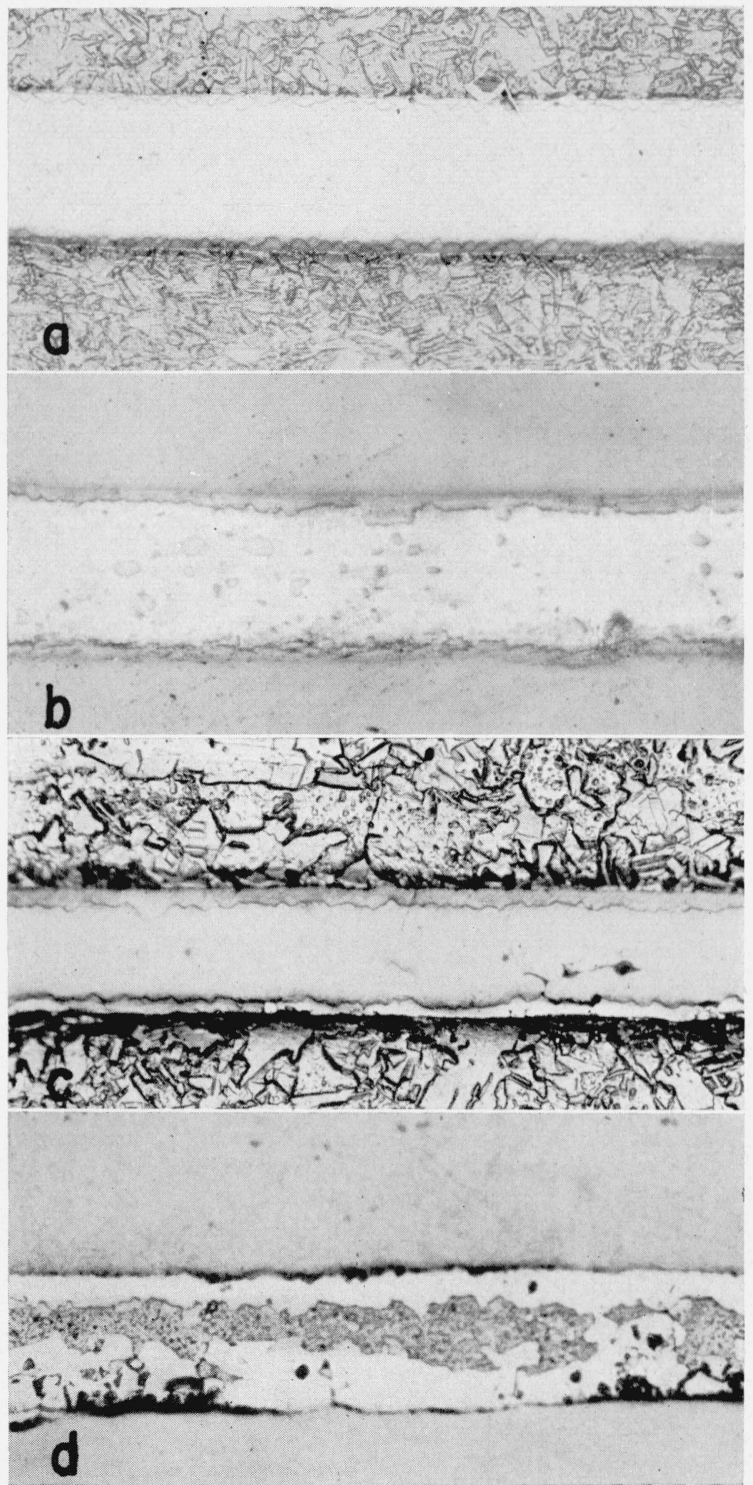

FIGURE 6.-Structural changes in the solder film in a copper-tube joint, (95-5) tinantimony solder, $\times 250$.

(a) Initial structure of solder film; note the bonding alloy layer, presumably not simple $\mathrm{Cu}_{3} \mathrm{Sn}$; etched; (b) solder film in a joint maintained at $250^{\circ} \mathrm{F}$ for 6,000 hours under a tensile shear stress of $175 \mathrm{lb} / \mathrm{in} .^{2}$ for 2,200 hours and $80 \mathrm{lb} / \mathrm{in}^{2}, 3,800$ hours, unetched. Note increase in the bonding laver; (c) solder film in a joint maintained at $250^{\circ} \mathrm{F}$ for 9,100 hours under a tensile shear stress of $80 \mathrm{lb} / \mathrm{in}^{2}$, etched; (d) solder film in a joint maintained at $325^{\circ} \mathrm{F}$ for 7,500 hours under a tensile shear stress of $153 \mathrm{lb} / \mathrm{in} . .^{2}$, unetched. Compare figure 3 (c). 

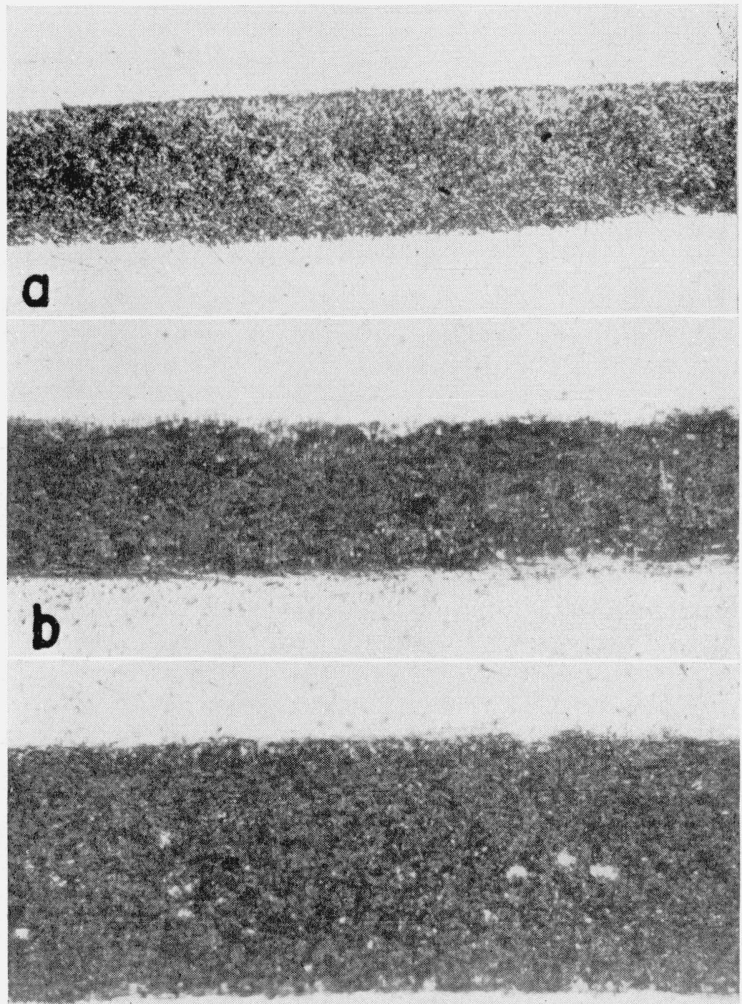

\section{C}

FIGURE 7.- Structural changes in the solder film in a copper-tube joint, (95-5) leadsilver solder, unetched, $\times 250$.

(a) Initial structure of solder film; (b) solder film in a copper-tube joint maintained at $250^{\circ} \mathrm{F}$ for 13,200 hours under a tensile shear stress of $220 \mathrm{lb} / \mathrm{in}^{2}$. Note coalescence of the silver constituent within the solder; (c) solder film in a copper-tube joint maintained at $325^{\circ} \mathrm{F}$ for 12,500 hours under a tensile shear stress of $105 \mathrm{lb} / \mathrm{in}^{2}$. Note increased coalescence of the silver constituent of the solder. 

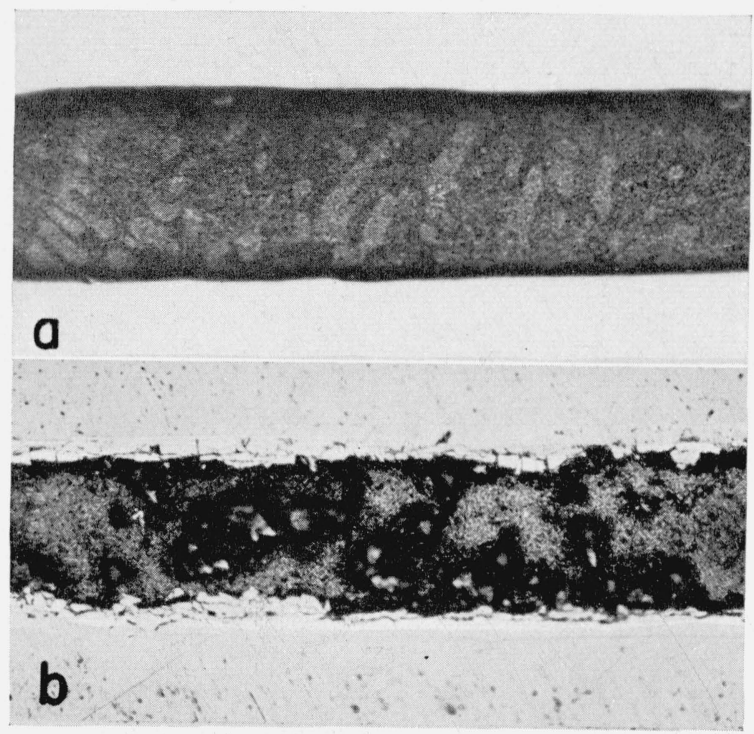

FIGURE 8.- Structural changes in the solder film in a copper-tube joint, (85.4-14.3$0.3)$ lead-cadmium-zinc solder, unetched, $\times 250$.

(a) Initial structure of the solder film; no bonding layer was detected; (b) solder film in a joint maintained at $325^{\circ} \mathrm{F}$ for 5,000 hours under a tensile shear stress of $90 \mathrm{lb} / \mathrm{in}^{2}$. Note the pronounced development of the bonding-alloy layer, $\mathrm{Cd}_{3} \mathrm{Cu}_{2}$.

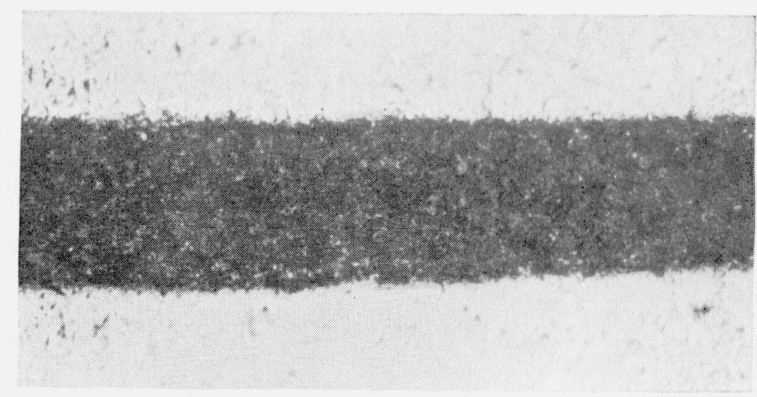

FIGURE 9.-Initial structure of lead-solder film in a copper-tube joint, etched, $\times 250$. 

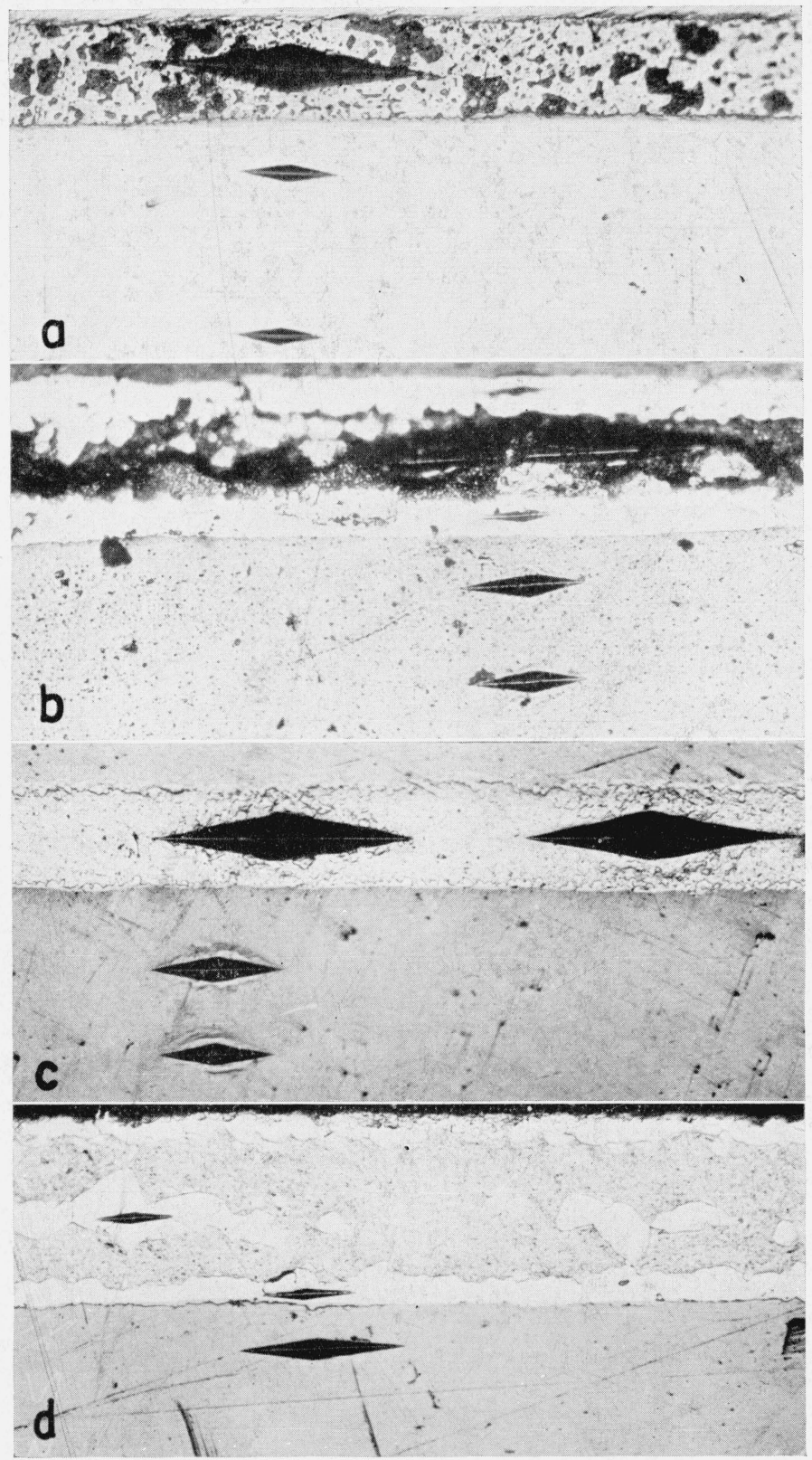

FIGURE 10.-Indentations in the constituent parts of soldered copper-tube joints produced by the Knoop hardness indenter with 25-g load, $\times 250$.

(a) Initial condition of a solder film of (50-50) tin-lead solder. Indentation hardness; solder, 14; copper base, 102; (b) solder film similar to (a) after 12,000 hours at $250^{\circ} \mathrm{F}$. Indentation hardness; center of solder film, 15; bonding-alloy layer, 196; copper base, 110; (c) initial condition of a solder film of (95-5) tin-antimony solder. Indentation hardness; solder, 22; copper base, 113; (d) solder film similar to (c) after 7,500 hours at $325^{\circ} \mathrm{F}$. Indentation hardness; center of solder film, 19; bonding-alloy layer, 165; copper base, 99. Note the shatter cracks in the bonding layer adjacent to the indentations. 
tin-base solders occurs readily if the solder is molten and the copper is clean and at the proper soldering temperature. It can also occur, but at a much slower rate, after the solder has solidified, provided the soldered joint is maintained for a long time at a sufficiently high temperature.

\section{METALLOGRAPHIC STUDY OF SOLDERED JOINTS- RESULTS AND DISCUSSION}

\section{GENERAL DISCUSSION}

Soldered sleeve joints of the kind shown in figure 1 were used to supply the specimens for metallographic examination. The joined

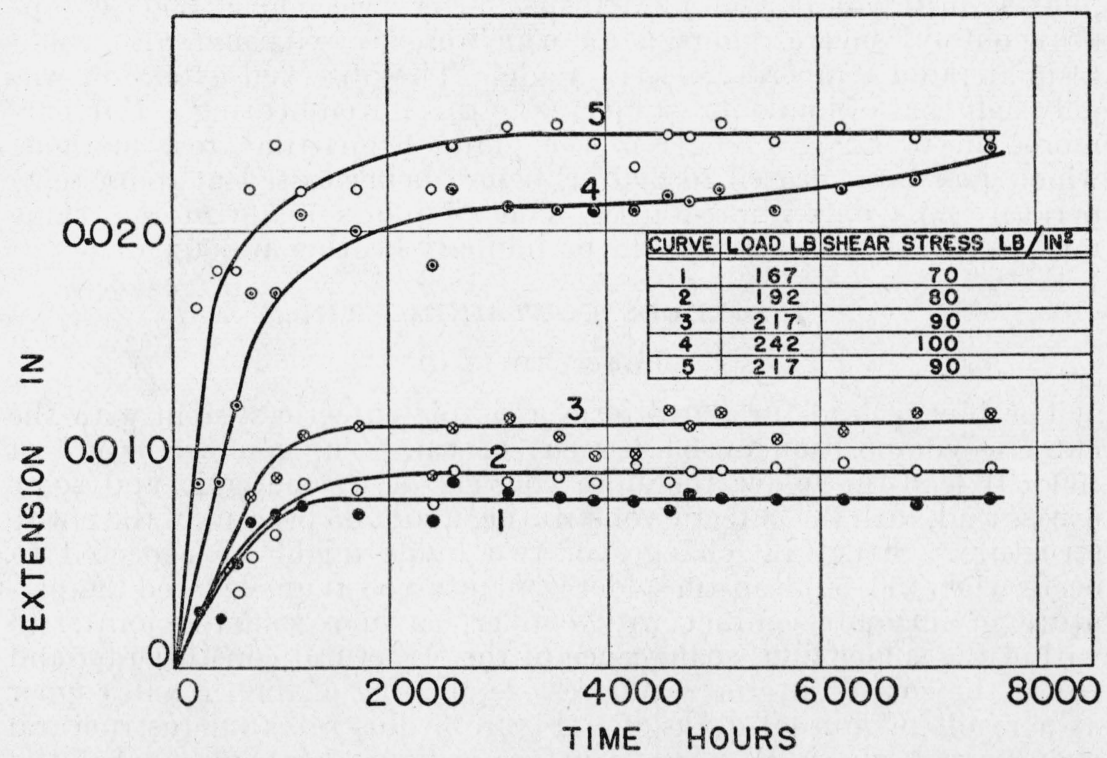

Figure 2.-Extension-time curves of joints soldered with (50-50) tin-lead solder maintained at $250^{\circ} \mathrm{F}$ for 7,500 hours.

Curve 5 for cast-brass (85-5-5-5) coupling; others for copper couplings; diametral clearance, 0.004 inch.

tubular specimens were maintained for long periods, usually under tensile load, at the temperature whose effect was being considered. The loading conditions are given in the legend for the corresponding micrograph in the succeeding figures. In some cases, after a specimen had been cut from the joint, the heating of the joint was continued under no load.

The solders used in making the joints were those reported in the previous studies $[1,2]$. The nominal percentage compositions of the solders containing tin were $(50-50)$ tin-lead, (95-5) tin-antimony, $(60-39-1)$ lead-tin-antimony, and (95-5) lead-tin. The tin-free leadbase solders used were (85.4-14.3-0.3) lead-cadmium-zinc, (95-5) leadsilver, and high-purity lead.

In figure 2 are given time-extension curves of a series of jointed specimens made with (50-50) tin-lead solder maintained for long periods at $250^{\circ} \mathrm{F}$ under suitable tensile loads to produce the designated shear stresses. Two phenomena are outstanding in these 
curves. During the initial stage of heating, approximately 1,000 hours, extension occurred in each of the joints, the extension increasing as the shear stress was increased. With increasing heating period, the resistance of the joint to extension at all of the applied stresses increased, so that after 2,000 hours' heating (approximately) the extension rate was negligible and remained so for the remainder of the 7,800 hours' heating period. It is evident that a change occurred within the joint, presumably in the soldered film, during the initial heating and that this change was nearly completed after 2,000 hours. At the conclusion of the test, the strength of the joint was measured by a short-time tensile test. The load required to fracture a joint was approximately seven-tenths of that needed for a freshly soldered joint.

To obtain further information on the change produced in a soldered joint by heat, comparison jointed specimens were held at $600^{\circ} \mathrm{F}$ (approximately) several hours, after which creep (extension with time) tests at room temperature were made. The observed extension was only half that of joints not subjected to this initial heating. Furtbermore, the breaking strength of the joints (short-time test method) which had been heated to $600^{\circ} \mathrm{F}$ before being tested at room temperature was only three-fourths that of joints made in the same manner but not subjected to the preliminary heating at $600^{\circ} \mathrm{F}$.

\section{SOLDERS CONTAINING TIN}

(a) (50-50) TIN-LEAD

The binary lead-tin alloys form a simple eutectic system with the eutectic composition at 63 percent of tin. The microstructure of (50-50) lead-tin solder therefore consists of the eutectic and some excess lead, with the eutectic constituting about 85 percent of the entire structure. Structural changes of two kinds might be expected to occur when (50-50) lead-tin solder is maintained at an elevated temperature in intimate contact with copper, as in a soldered joint: (a) within the solder film, coalescence of the structural constituents; and (b) at the copper interface, progressive alloying of the tin and copper as a result of mutual diffusion. Figure 3 illustrates microstructural changes of both kinds. The structure in figure $3(a)$ is typical of the freshly soldered joint. The middle portion of the solder film, which is the structure of the unaltered solder, is characterized by the excess lead, occurring as dendrites, in a eutectic matrix. Adjacent to the copper, a thin alloy layer, the "bonding" alloy, is formed by the alloying of the tin of the molten solder and the copper. Continued heating at a moderately elevated temperature, $250^{\circ} \mathrm{F}$ (fig. $3, b$ ), results in pronounced coalescence of the constituents within the solder film and an increase in thickness of the bonding-alloy layer. Presumably also, composition changes toward the middle of the solder film occurred as a result of inward diffusion of copper, which, however, is not detectable in the microstructure. With long-continued heating, the structural change becomes more pronounced, particularly in the copper-bearing alloy layer. This layer, at first at least, probably consists chiefly of the intermetallic compound $\mathrm{Cu}_{3} \mathrm{Sn}$. Another constituent of the copper-tin system, of higher copper content, was observed in some joints which had been heated for very long periods (fig. $3, d$ ). It is also faintly visible in figure $3(c)$.

A study of the relative hardness of the various portions of the soldered joint was made with a pyramidal diamond indenter [3]. 
Measurements were made on the solder film in its original condition, figure $3(a)$, and on the bonding-alloy layers and coalesced constituents of the films after 7,500 and 12,000 hours at $250^{\circ} \mathrm{F}$ (fig. $3, b$ and $c$ ). An indenting load of $25 \mathrm{~g}$ was used and the indentation numbers tabulated (table 1) were calculated from the lengths of the indentations by the method of Knoop, Peters, and Emerson [3]. It was not possible to make indentations separately on the two bonding-alloy layers shown in figure $3(d)$ because of their small widths. Brinell and Vickers numbers were also determined on the copper tubing to show the relationship between these and the Knoop numbers. While these same relationships do not necessarily hold for estimating Brinell and Vickers numbers equivalent to the Knoop numbers obtained on the constituents in the solder films, it is believed that the comparisons on the copper serve as a fair approximation.

TABLE 1.-Hardness of constituent parts of soldered copper tube sleeve joints (Knoop pyramidal diamond microindenter, 25-g load)

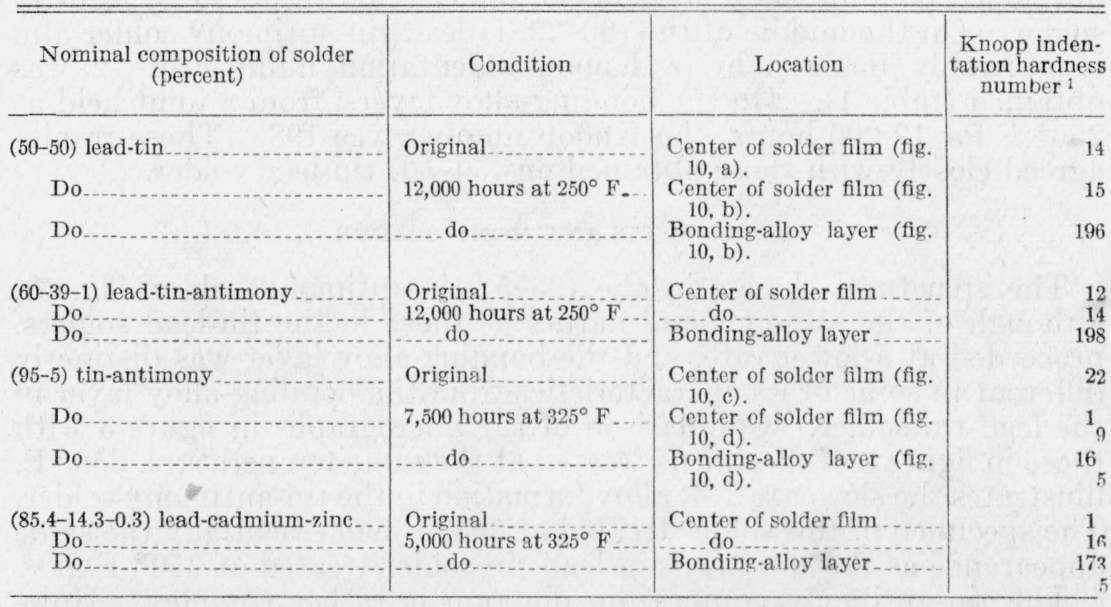

1 The average Knoop indentation hardness number of the copper tubing, 8 specimens, transverse sections, was $107 \pm 8$. The Brinell hardness number, 15 -kg load, $1 / 16$-inch ball, of copper tubing (99 Knoop indentation) was 101; (115 Knoop indentation) 114. The Vickers hardness number, 15-kg load, $136^{\circ}$ square base pyramid, of same specimens was 107 and 120 , respectively.

The hardness of the coalesced particles of tin-lead eutectic (fig. 3, $c$ ) as was expected was not significantly different from that of the solder in its original condition in the film (fig. $3, a$ ) in which the eutectic was more uniformly dispersed. Both have essentially the same constitution. The hardness numbers obtained on the thin film have the same general magnitude as those obtained on tin-lead alloys in more massive form. The results may be considered as indicating also that no significant amount of copper had diffused as far as the middle of the film.

The hardness of the bonding-alloy layers adjacent to the copper is surprisingly high, being of the order of that of structural steels having a tensile strength of about $100,000 \mathrm{lb} / \mathrm{in}^{2}{ }^{2}$ These layers are considered to consist essentially of the copper-tin intermetallic compound. It is characteristic of intermetallic compounds of this kind that their hardness is much greater than that of any of the constituent metals. The shattered condition of the hard layers (fig. $3, c$ ) is evidence that brittleness accompanies the greatly increased hardness. 
Increased shear strength would also be expected in the hard, brittle layers and could account for the observed increase in the resistance of the joints to extension under tensile loads. Such joints, when pulled apart, whether in a short- or a long-time test, failed without appreciable extension as the load was increased to the rupturing point. Freshly made joints, in similar tests, showed increasing extension with increase in load practically to the breaking point.

\section{(b) (60-39-1) LEAD-TIN-ANTIMONY AND (95-5) LEAD-TIN}

The structural changes which were observed in the (60-39-1) leadtin-antimony solder films (fig. 4) and in the (95-5) lead-tin solder (fig. 5) were of the same general nature as those described above. In the (95-5) lead-tin solder, however, the alloy layers were not nearly so thick and well developed, probably because of the relatively low tin content of the alloy.

Indentation-hardness tests could not be made on the thin, poorly developed bonding-alloy layer of the solder film of the $(95-5)$ lead-tin solder. On the middle of the (60-39-1) lead-tin-antimony solder film in a freshly made joint, a Knoop indentation number of 12 was obtained (table 1). On the bonding-alloy layers, from a joint held at $250^{\circ} \mathrm{F}$ for 12,000 hours, the Knoop number was 198 . These results agreed closely with those obtained on (50-50) tin-lead solder.

\section{(c) (95-5) TIN-ANTIMONY SOLDER}

The structural change in the (95-5) tin-antimony solder (fig. 6), although of the same general nature as those in the tin-lead solders, proceeded at a lower rate, and the bonding-alloy layer was distinctly different in some of its characteristics from the bonding-alloy layer in the lead-tin solder. Comparison of the micrographs in figure 3 with those in figure 6 of specimens treated at the same temperature, $250^{\circ} \mathrm{F}$, illustrates the slower rate of alloy formation in the tin-antimony solder. The specimen of this solder treated at $325^{\circ} \mathrm{F}$ had essentially the same appearance as the specimens of lead-tin solder treated at $250^{\circ} \mathrm{F}$.

The tin-antimony equilibrium diagram is rather complex. However, so far as the (95-5) tin-antimony solder is concerned, it is very simple, since tin is capable of holding approximately 9 percent of antimony in solid solution. The temperature interval within which the $(95-5)$ solid solution is partially molten is relatively very narrow. Coalescence within the solid solution on continued heating is not to be expected until its composition has been substantially changed by diffusion of copper into it (fig. $6, b$ ).

In the middle of the film of (95-5) tin-antimony solder in a freshly made joint, a Knoop number of 22 was obtained, showing that this solder is harder than the tin-lead solders (table 1). This result is in agreement with the higher strength at room temperature shown by joints made with this solder $[1,2]$.

In the diffusion zone bordering the film of (95-5) tin-antimony solder in a joint held at $325^{\circ} \mathrm{F}$ for 5,000 hours (fig. 6, $d$ ), a Knoop number of 200 was obtained, the same as in the corresponding diffusion zone of the tin-lead solders. These zones also probably consist of copper-tin intermetallic compound, possibly altered somewhat by antimony. This was indicated by a shattering effect when the indentations (fig. $10, b$ ) were made. 


\section{LEAD-BASE TIN-FREE SOLDERS}

(a) LEAD-SILVER

The solders of this group differed among themselves in their response to long-continued heating. The (95-5) lead-silver solder exhibited no marked tendency toward alloy formation with the adjacent copper, which was found to be so characteristic of the lead-tin solders.

Lead and silver form a simple eutectic series of binary alloys. The silver content of the eutectic is 2.3 percent and the eutectic temperature, $304^{\circ} \mathrm{C}\left(579^{\circ} \mathrm{F}\right)$. On long-continued heating, coalescence of the eutectic occurs, and the silver constituent becomes a more prominent feature of the microstructure (fig. 7).

\section{(b) LEAD-CADMIUM-ZINC}

The lead-cadmium alloy system is a simple eutectic one. The two constituent metals are soluble in each other to a limited extent. The eutectic of these solid solutions corresponds to a cadmium content of 17.4 percent by weight, the eutectic temperature being $240^{\circ} \mathrm{C}$ $\left(464^{\circ} \mathrm{F}\right)$. The solder used (14 percent of cadmium), therefore, consists structurally of a eutectic matrix in which the excess constituent, lead, is embedded (fig. 8, $a$ ). The small amount of zinc (0.3 percent) is not considered to affect the properties of the finished joint. The changes observed in the microstructure of the solder films on copper after long-continued heating were similar to those described for the solders containing tin. Coalescence of the eutectic constituents is to be expected and is shown in figure $8(b)$. A well-developed bondingalloy layer also was developed as a result of the diffusion between the cadmium and copper, although a distinctly higher temperature was required. Presumably, the constituent in this layer is the intermetallic compound $\mathrm{Cd}_{3} \mathrm{Cu}_{2}$.

Indentation-hardness tests on the middle of the solder film of a freshly made joint showed a Knoop number of 15 , which is at the same hardness level as that of tin-lead solders similarly tested (table 1 ). In a joint made with the same solder and held at $325^{\circ} \mathrm{F}$ for 5,000 hours, a Knoop number less than 13 was obtained in the middle of the solder film, indicating that coalescence of the eutectic constituents had resulted in a softening effect. In the diffusion zone near the bond, a Knoop number of 175 was obtained, which shows a hardness significantly lower than that of the copper-tin compound formed in the tin-alloy solders.

(c) HIGH-PURITY LEAD

As would be expected, high-purity lead when used as a solder on copper had no detectable alloying action, either in a freshly made joint or in the joints held for long periods of time at temperatures up to $325^{\circ} \mathrm{F}$ (fig. 9 ).

\section{CONCLUSIONS}

1. Investigations previously reported have clearly shown the reliability of soldered sleeve joints in copper-tube lines used in domestic plumbing and for various other purposes. A limitation on the maximum temperature for elevated temperature service appeared necessary, however, especially for joints made with solder containing tin.

2. Joints made with solder containing tin were considered to be entirely satisfactory for service in which the temperatures did not ex- 
ceed $250^{\circ} \mathrm{F}$. Some lead-base solders, containing no tin, were considered reliable for use at somewhat higher temperatures, $325^{\circ} \mathrm{F}$ being the maximum.

3. A criterion for the complete evaluation of soldered joints of the type discussed here for extended use at elevated temperature is not furnished by strength measurements alone. The possibility of bond deterioration under long-continued heating must be considered also.

4. Creep, or time-extension, tests at a constant elevated temperature of joints made with (50-50) lead-tin solder showed an initial period, approximately 1,000 hours, during which extension within the soldered joint normally occurred, the magnitude of the extension being determined by the shear stress acting in the joint. However, this initial behavior was followed by a very great increase in creep resistance in the joint, and during the remainder of the period at the elevated temperature substantially no extension occurred. Such joints showed a marked decrease in strength, as determined subsequently at room temperature by short-time tensile tests.

5 . To determine the nature of the change in the solder underlying this behavior of the joint, a metallographic study of the microstructure of soldered sleeve joints in copper tubing was made. Joints made with solders containing tin and maintained for long periods at $250^{\circ} \mathrm{F}$ showed coalescence of the microstructural constituents and progressive formation of a layer of a new constituent adjacent to the copper. This is evidently the intermetallic compound, designated as the "bondingalloy layer" and consisting of $\mathrm{Cu}_{3} \mathrm{Sn}$, which results from alloying of the tin with copper by diffusion.

6. Hardness measurements of the bonding-alloy layer by the Knoop microindentation method showed it to be very much harder than the solder, the indentation harness numbers for $(50-50)$ lead-tin solder and alloy layer being in the approximate ratio 14:196. The indentation hardness of the bonding alloy varied somewhat for the different solders but was always higher than that of the copper, which averaged 107. Fragmentation of the bonding-alloy layer was observed to occur in some cases as a result of the indentation hardness tests. The thickness of the hard, brittle bonding-alloy layer was dependent upon the initial tin content of the solder.

7. Tin-antimony solder used in sleeve joints, when maintained at an elevated temperature, behaved in essentially the same manner as tin-lead solder. The resulting bonding-alloy layer possessed the same general characteristics, although the hardness was somewhat lower than that of the bonding layer in the lead-tin solder film.

8. The lead-cadmium alloy showed a progressive growth of a bonding-alloy layer at elevated temperature which did not differ markedly in its characteristics from the corresponding constituent in the leadtin solder films.

9. Pronounced coalescence of the structural constituents occurred in the lead-silver solder maintained at elevated temperature, but substantially no increase in the bonding layer was detected. No evidence of alloying with the copper base was observed in the lead-solder joints after long-continued heating. 
The authors gratefully acknowledge their indebtedness to a number of their associates in the Division of Metallurgy, National Bureau of Standards, and particularly to H. K. Herschman for carrying out the hardness determinations, and to T. D. Brown for his assistance in the metallographic studies of the lead-base solders.

\section{REFERENCES}

[1] A. R. Maupin and W. H. Swanger, Strength of soft-soldered joints in copper tubing, Building Materials and Structures (1938) NBS Rep. BMS58.

[2] A. R. Maupin and W. H. Swanger, Strength of sleeve joints in copper tubing made with various lead-base solders, Building Materials and Structures (1942) NBS Rep. BMS83.

[3] F. Knoop, C. G. Peters, and W. B. Emerson, A sensitive pyramidal-diamond tool for indentation measurements, J. Research NBS 23, 39 (1939) RP1220.

[4] S. J. Nightingale, The jointing of metals, Part I. Soft solders and soldered joints, Brit. Non-Ferrous Metals Research Assn., Research Reports, No. C 234/214 (Dec. 1936).

[5] R. Chadwick, The influence of surface alloying on the strength of soft soldered joints, J. Inst. Metals 62, 277 (1938).

Washington, January 28, 1942. 